\title{
Wildfire Monitoring and Detection System Using Wireless Sensor Network: A Case Study of Tanzania
}

\author{
Albert S. Lutakamale, Shubi Kaijage \\ Department of Communication Science and Engineering, Nelson Mandela African Institution of Science and Technology, Arusha, \\ Tanzania \\ Email: lutakamalea@nm-aist.ac.tz, shubi.kaijage@nm-aistac.tz
}

How to cite this paper: Lutakamale, A.S. and Kaijage, S. (2017) Wildfire Monitoring and Detection System Using Wireless Sensor Network: A Case Study of Tanzania. Wireless Sensor Network, 9, 274-289. https://doi.org/10.4236/wsn.2017.98015

Received: July 19, 2017

Accepted: August 15, 2017

Published: August 18, 2017

Copyright ( $) 2017$ by authors and Scientific Research Publishing Inc. This work is licensed under the Creative Commons Attribution International License (CC BY 4.0).

http://creativecommons.org/licenses/by/4.0/ (c) (i) Open Access

\begin{abstract}
This paper proposes a wildfire monitoring and detection system based on wireless sensor network. This system detects fire by monitoring surrounding temperature, humidity and smoke. Once fire is detected, a warning message containing probable location of that fire is immediately sent to the responsible authority over cellular network. In order for the system to be more effective, communities living near forests or national parks can send warning messages through the same system to the responsible authority using their mobile handsets once they witness wildfire or illegal activities. For the system to be fully functional, the only requirement is the availability of cellular network coverage in forests or national parks to enable short message services to take place. The system prototype is developed using Arduino microcontroller, several sensors to detect temperature, relative humidity and smoke as well as wireless network connection modules. At the control center Telerivet messaging platform is used to design the messaging service. The experimental results justify the capability of the proposed system in detecting wildfire in real time.
\end{abstract}

\section{Keywords}

Wildfire, Monitoring, Detection, Wireless Sensor Network, Forests, Cellular Network Coverage, Telerivet

\section{Introduction}

Wildfire is a kind of fire that occurs in the forests or reserved national parks. It starts as small fire but eventually turns into a huge fire due to some favorable con- 
ditions such as presence of dry trees and grasses as well as strong winds in the forests. The outcome may be due to failure of responsible authorities of getting early information about fire as soon as it starts so that they could be able to control before it turns into a huge fire.

Human activities like clearing field for cultivation, charcoal burning or smoking can cause wildfire to occur. Broken glasses can be another source of wildfire because sometimes they can act as collective lens focusing sun light on a small spot for a length of time, a condition that could trigger fire [1].

Economic activities such as tourism can be affected in a negative way by wildfires due to damages it causes to the vegetation of ecosystems [2]. Wildfires are a constant threat to ecological systems of forests and human safety especially in regions which present hot climate [3].

Just like other countries, Tanzania is affected by wildfires each year causing deaths of people and wild animals as well as damage to valuable infrastructures leading to loss of some valuable plants and animal species. According to the reported analysis of 2012 for Tanzania using MODIS (Moderate Resolution Imaging Spectroradiometer), in average Tanzania loses over 11 million hectares of forests and woodlands each year (ranging between 8.5 and 12.9 million hectares) [4]. This is equivalent to about $9 \%-14 \%$ of Tanzania's total land area. In another study conducted in Tanzania by Finnish government in collaboration with Tanzania's government funded by FAO (Food and Agriculture Organization), it points out that between the year 2000 and 2012 there have been over 900,000 cases of wildfire detected by satellite with the number of fires occurring each year reasonably consistent [5]. In this study it was found out that in 11 out of 23 Game Reserves had an average of 100,000 hectares of burnt land per year; 11 of the 69 Game Controlled Areas had a total of more than 1 million hectares of burnt area yearly between the year 2000 and 2011. Serengeti, Ruaha and Katavi National Parks were reported to approximately have 16.5 million hectares of burnt area [5].

A lot of studies based on wireless sensor networks have been done by researchers worldwide in order to come up with systems capable of monitoring and detecting wildfire. Bolourchi \& Uysal in 2013 came up with a research work that proposes the use of wireless sensor network (WSN) for data harvesting to be used as raw input data into a control system that they developed [6]. They choose fire detection to illustrate the Intelligent Decision Making (IDM) capability of the system and developed Fuzzy Logic algorithm using temperature, smoke, light, humidity and distance as functions. Probability of fire based on fuzzy rules using the status of the functions is presented by simulating the developed system on the Matlab software. The weakness in this research is that it is merely a theoretical work based on simulation on the Matlab software for the purpose of finding the probability of occurrence of fire. The system is not tested in the really environment to give out a clue on how it will behave.

A research work by Lloret et al. in 2009 recommended a wireless sensor net- 
work deployment for rural and forest fire detection and verification [7]. This system uses IP (Internet Protocol) cameras in a wireless network in order to detect and verify fire in rural and forest areas. The system consists of multiple sensors and access points to detect fire and send a sensor alarm through the wireless network to a central server. The central server selects the closest wireless cameras to the multi-sensor, based on a software application, which are rotated to the sensor that raised the alarm, and sends them a message in order to receive real-time images from the zone. This system requires better internet coverage in rural and forest areas. In Tanzania the forests and rural areas don't have good coverage of internet and thus if this system is deployed it won't function effectively and efficiently as intended. Another downside of this system is the use of IP cameras which consumes more energy and requires large bandwidth to be able to send the images. The overall cost of implementing this system for a developing country like Tanzania is too high.

In 2016, forest monitoring and wildland early fire detection system by a hierarchical wireless sensor network was reported [8]. The research work adopts a standard wireless sensor network approach using two levels for the nodes, central nodes and sensor nodes, and some optimization techniques to minimize power requirements. During network deployment, each sensor would record its delocalization based on GPS (Global Positioning System) information. Sensor nodes capture data from the environment that are uploaded to the central nodes, which transfer all the information to the system middleware. The transfer of sensor data from the central node to the middleware for this system is in terms of packets, so for it to function there has to be internet coverage which is a disadvantage if the system has to be implemented in Tanzania due to unreliable nature of internet services in forests and remote areas. Also to realize the full potential of the system it has to be integrated with all key players in firefighting operations such as fire brigades, communication systems, and aerial, coordination, and land means so the cost of implementation is high.

Wang et al. in 2015 suggested forest fire warning system based on Geographical Information Systems (GIS) and WSNs [9]. This system is designed and developed with GIS and WSNs. A number of sensor nodes which constitutes the wireless sensor networks are developed in the region which can measure the concentration of carbon monoxide, $\mathrm{CO}$ and smog and detect flame and gauge the temperature and humidity. The data including position information are sent to the monitoring center through the GPRS (General Packet Radio Service) net and real-time displayed on the electronic map. The weakness of this approach is that it requires constant presence of people at the monitoring centre to analyze data received from the sensing nodes in order to determine whether there is wildfire or not. To guarantee the constant presence of people is somehow unrealistic/hard.

Chauhan et al. in 2013 came up with artificial neural network-based forest fire detection system using wireless sensor network [10]. The proposed framework 
in this research mainly describes the data collection from designed data acquisition system and then its classification. The wireless transmission of sensor node data is done using BTBee module and also artificial neural network approach i.e. support vector machine (SVM) is applied for classification of collected data. For someone to be able to deploy and implement this system has to be equipped with a lot of skills such as knowledge on support vector machine, multilayer perception polynomial and quadratic and radial basis function.

In 2008, Zhang et al. presented a forest fire detection system based on ZigBee wireless sensor network [11]. The topology structure of the system is an adaptation of a cluster-tree in order for the information path to take less memory space. The hardware circuitry of the network node is based on a CC2430 chip. The environmental parameters detected are temperature and humidity. Communication between gateway and monitoring centre is done through GPRS module. Processor chip used at the gateway is PXA255 from Intel Company. The downside of this system is requirement of internet within forest areas all the time for it to function.

Hefeeda \& Bagheri in 2009 proposed forest fire modeling and early detection using wireless sensor networks [12]. This system is designed based on Fire Weather Index (FWI) which is one of the most comprehensive forest fire dangers rating system used in the world. The primary part of this research was to first collect real data and analyze the behavior of the fire indexes for the wide ranges of weather conditions mainly temperature and humidity. They then model the forest fire detection problem as a k-coverage problem $(k \geq 1)$ in wireless sensor networks. The final part of their design was to propose a distributed k-coverage algorithm and conduct an extensive simulation study to evaluate and compare the performance of their algorithm with other algorithms. Their algorithm could be extended to address several issues relevant to forest fire detection systems like providing different coverage degrees at different sub areas of the forest. The weakness of this research is that it is only for developing an algorithm that will address the issue of forest fire detection coverage within a particular forest and not the designing of the actual system.

Owayjan et al. in 2014 published their research work about forest fire detection and alerting system which they call it Firoxio [13]. This system is based on wireless sensor network where by standalone boxes acting as sensor node having different types of sensors for detecting temperature, humidity, smoke and methane are deployed in the forests. The drawback of this system is the fact that it requires constant presence of internet within the forests for it to be fully functional, a condition which is hard to be met in a country like Tanzania.

Looking at the currently existing systems for monitoring and detection of wildfire based on wireless sensor network and the severity of wildfire problem in Tanzania, there is a need of coming up with a system which will suit Tanzania environment and that of other developing countries. The work presented in this paper will help to minimize the damages to the vegetation ecosystems as well as 
minimize deaths of people and destruction of valuable properties. This is achieved through giving out information about wildfire to the responsible people/authority as soon as it occurs to give them enough time to control it before it causes great damage. Another importance of this work is the involvement of communities around forests and national parks in conserving the forests by giving out information to the responsible people/authority by using their mobile handsets whenever they witness wildfire or illegal activities (such as charcoal burning, illegal logging, poaching etc.) taking place in the forests.

The rest of this paper is organized as follows: Section 2 presents equipment used and designing procedures of the system prototype, Section 3 provides prototype testing results and corresponding discussions and Section 4 gives out conclusive remarks of this research work.

\section{Prototype Development}

This system consists of three main parts: The Sensing Node, The Gateway Node and The Control Center. The sensing node is for detecting the presence of fire by monitoring surrounding temperature, humidity and presence of thick smoke. These three parameters are chosen because wildfire is always accompanied with thick smoke, increase in surrounding temperature and decrease in relative humidity due to dryness of air. The gateway node acts as the coordinator, it receives warning notifications in terms of text messages from various sensing nodes and generates a wildfire notification message which contains probable location of where that fire is and sends it to the control center. The responsibilities of the control center is to receive wildfire notification from various gateway nodes as well as wildfire and illegal activities notification from villagers living around forest areas and automatically constructs and send warning messages to responsible people/authority. The system can have any number of gateway nodes depending on the size of forests or national parks that need to be covered. Each gateway node acts as a coordinator node to up to 10 sensing nodes. The distance between sensing node and gateway node depends on propagation power of the XBee module used; in this work the distance is between 100 - $120 \mathrm{~m}$. Figure 1 below shows system conceptual diagram.

\subsection{Sensing Node Designing}

The sensing node consists of sensors to sense fire parameters, ZigBee module for wireless transmission of data, microcontroller for controlling logic flow of events and the power supply to power up the system as shown in Figure 2 below.

Table 1 below summarizes the type, model and sensitivity of sensors used.

The sensors shown in Table 1 below were chosen because of their low power consumption, suitability for environmental monitoring and they are not expensive. Microcontroller and ZigBee module used are Arduino Uno and XBee series 2 from Digi International respectively. Arduino Uno microcontroller board which is based on the ATmega $328 \mathrm{P}$ microcontroller chip was chosen because of 


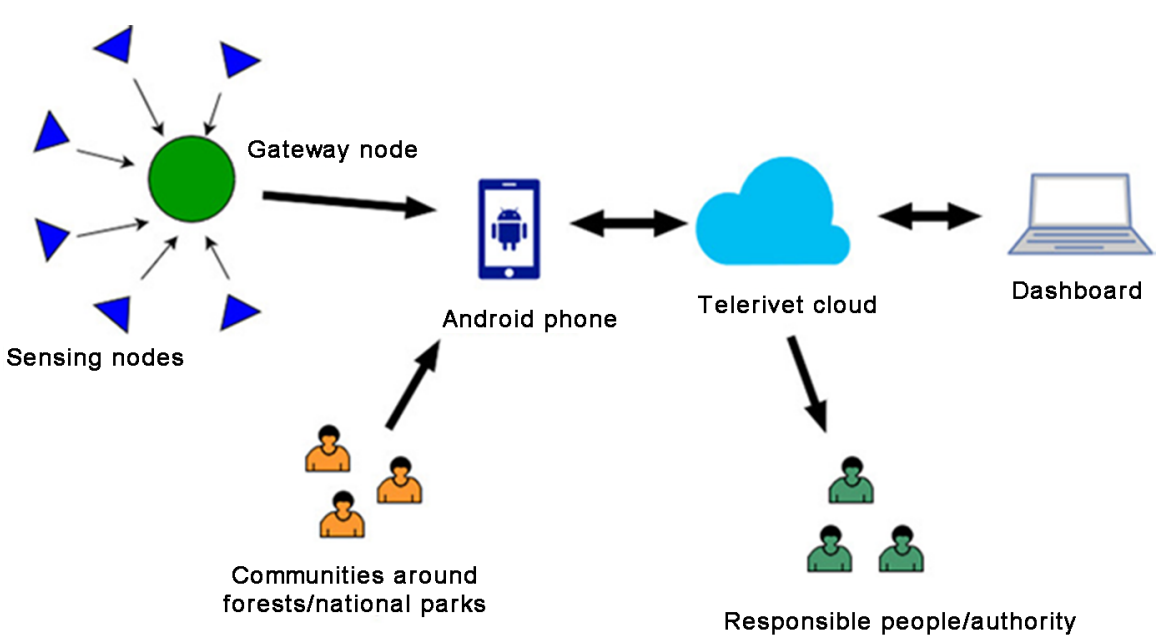

Figure 1. System conceptual diagram.

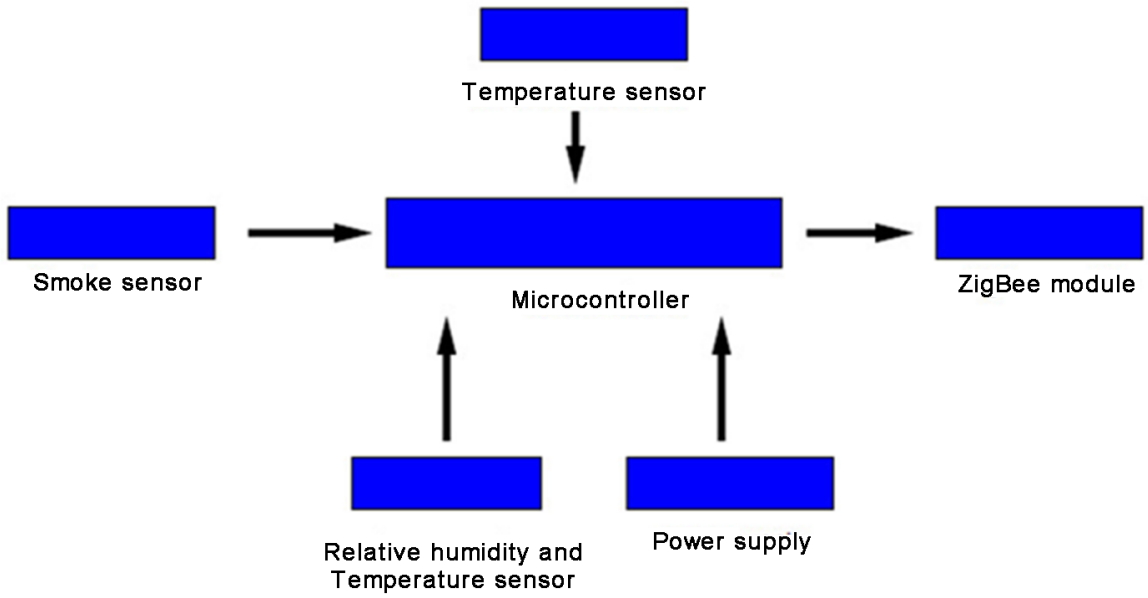

Figure 2. Sensing node block diagram.

Table 1. Type, model and sensitivity of sensors used.

\begin{tabular}{|c|c|c|c|c|}
\hline Sensor type & Sensor model & Sensor sensitivity & $\begin{array}{l}\text { Power } \\
\text { supply }\end{array}$ & Manufacturer \\
\hline Temperature sensor & LM35DZ & $0^{\circ} \mathrm{C}$ to $100^{\circ} \mathrm{C}$ & $5 \mathrm{~V}$ & $\begin{array}{c}\text { Texas } \\
\text { Instruments }\end{array}$ \\
\hline Smoke sensor & MQ-2 & $\begin{array}{l}\text { Smoke, LPG, Butane, } \\
\text { Propane, Methane, } \\
\text { Alcohol and Hydrogen }\end{array}$ & $5 \mathrm{~V}$ & $\begin{array}{c}\text { Sunrom } \\
\text { Electronics }\end{array}$ \\
\hline $\begin{array}{l}\text { Relative humidity and } \\
\text { temperature sensor }\end{array}$ & DHT22 & $\begin{array}{l}\text { Humidity: } 0 \% \text { to } 100 \% \mathrm{RH} \\
\text { Temperature: }-40^{\circ} \mathrm{C} \text { to } 125^{\circ} \mathrm{C}\end{array}$ & $5 \mathrm{~V}$ & Aosong \\
\hline
\end{tabular}

its stability, low power consumption, it is programmed using an open source Arduino Integrated Development Environment software and ability to provide $5 \mathrm{~V}$ and $3.3 \mathrm{~V}$ to sensors and XBee module respectively [14]. XBee series 2 module was chosen because it supports mesh networking, it is compatible with Arduino Uno, it is configured using X-CTU software which is free, it can communicate up to a range of $120 \mathrm{~m}$ (communication range can be increased by using PRO ver- 
sion of Xbee modules) and the fact that it operates at $2.4 \mathrm{GHz}$ band which is free to be used for industrial, scientific and medical research [15].

The Arduino Uno microcontroller board at the sensing node is powered using two rechargeable batteries of $3.7 \mathrm{~V}$ each (each battery having electric power of $3200 \mathrm{mAh}$ ) in series, connected to DC (Direct Current) to DC step up adjustable power supply. The DC to DC power booster used supports input voltage ranging from 3 to $34 \mathrm{~V} \mathrm{DC}$ and can give output voltage ranging from 4 to $35 \mathrm{~V} \mathrm{DC}$ with an output current of $3 \mathrm{~A}$. In this research the power booster is adjusted to give out a maximum output voltage of $9 \mathrm{~V}$ and a minimum output voltage of $7 \mathrm{~V}$ which is a recommended voltage range for the proper functioning of Arduino Uno microcontroller board. The rechargeable batteries can be connected to a solar panel to provide charging mechanism when the battery voltage becomes low. During testing of the prototype only the rechargeable batteries were used. Figure 3 below shows the flowchart at the sensing node.

\subsection{Gateway Node Designing}

The gateway node consists of the microcontroller for controlling logic flow of events, ZigBee module for receiving wildfire notification messages from the

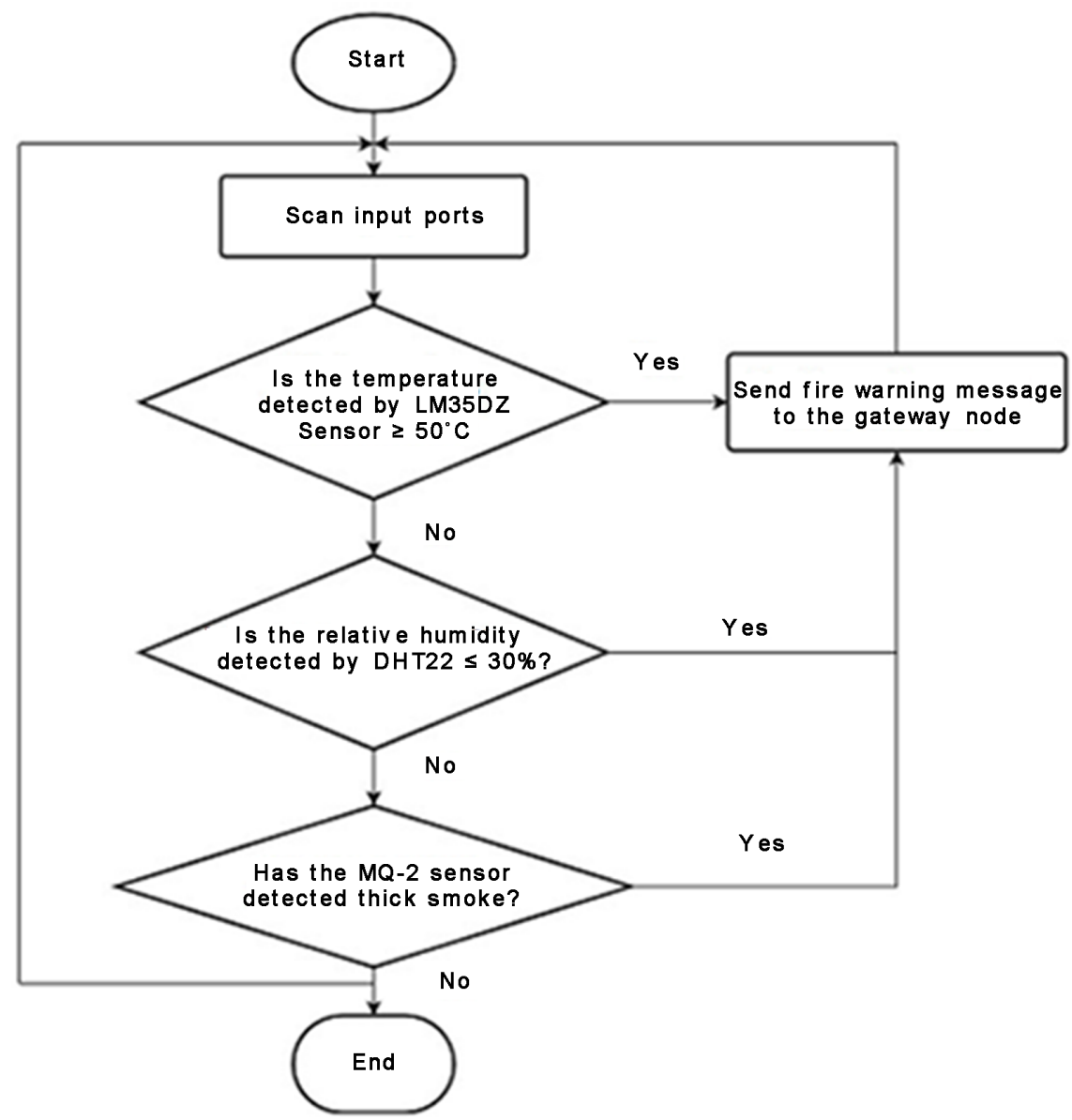

Figure 3. Functional flowchart at the sensing node. 
sensing node wirelessly, Elecrow's GSM (Global System for Mobile Communication)/GPRS shield for sending fire warning messages to the control center and power supply for powering up the node as shown in Figure 4 below.

Microcontroller and ZigBee module used are the same as the ones used in the sensing node. Elecrow's GSM/GPRS shield was chosen because it is configured using SIM800C module from SIMCOM which is a Quad-band module supporting 850/ 900/1800/1900 MHz frequencies [16]. In Tanzania mobile cellular communication uses 900 and $1800 \mathrm{MHz}$ frequency bands. The power supply to power the gateway node is the same as the one discussed in Section 2.1. Figure 5 below is the flowchart diagram which shows flow of events at the gateway node.

\subsection{The Control Center}

In this research work, the control center is designed using Telerivet Messaging Platform [17]. The main reason for choosing this messaging platform to design a control center is that Telerivet service provides an application that turns an Android phone into a low cost SMS (Short Message Service) gateway and by using this platform this work has avoided expenses associated with traditional SMS gateways like a need to purchase short code and negotiating with telecommunication companies [18].

A phone running android operating system is needed to act as a gateway for receiving and uploading received text messages into the Telerivet cloud servers. A laptop to act as a Telerivet dashboard will also be needed where the rules to control the incoming messages will be written.

In this research, the gateway nodes and communities living around forests and national parks communicates with control center through short message services (SMS), so the main requirement is the presence of cellular network coverage in those areas that will enable communications through SMS. There is no need of having reliable internet coverage in forests for the system to function because sensing nodes, gateway nodes as well as communities around it do not send notifications over the internet.

An android phone which acts as a gateway can be placed anywhere far away from the forests or national parks in order to have access to reliable internet

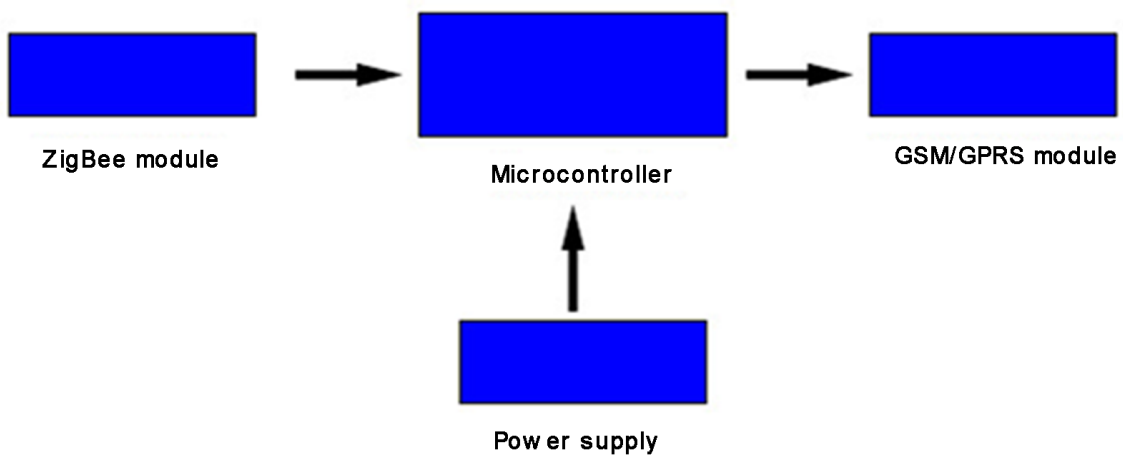

Figure 4. Gateway node block diagram. 


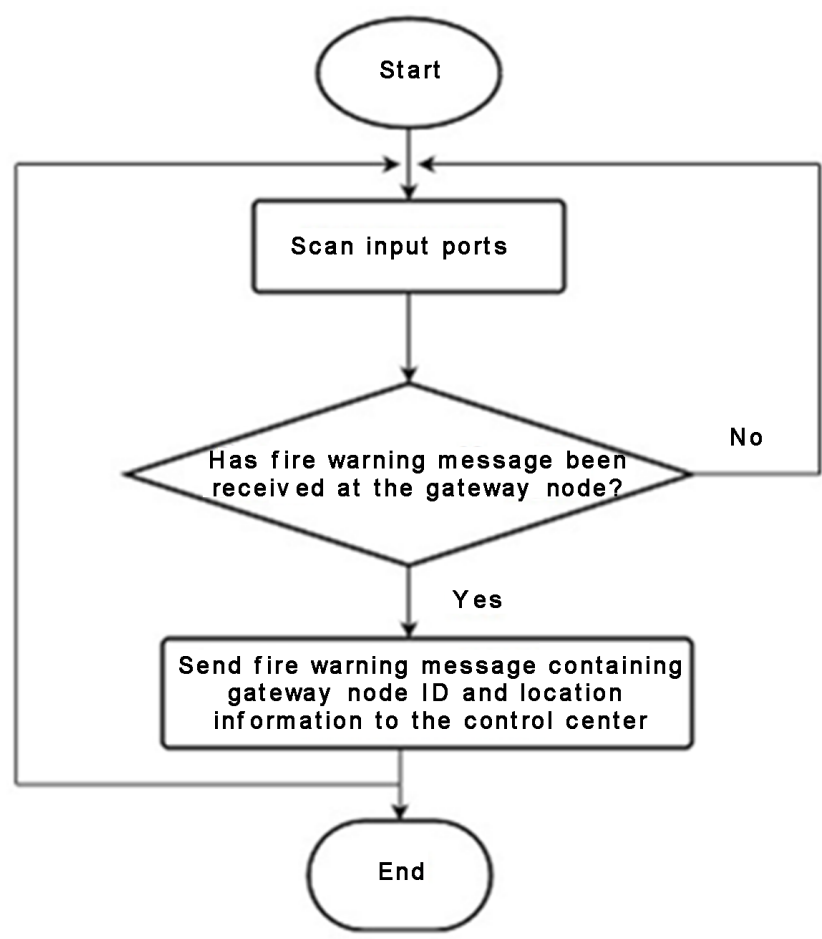

Figure 5. Functional flowchart at the gateway node.

services for it to be able to upload messages to the Telerivet cloud for processing. Figure 6 below shows the functional flowchart at the control center.

There are two sources which send messages to the control center, one is the gateway node and another one is the villager. When the gateway node receives wildfire notification from the sensing nodes it constructs any of the following three types of messages depending on which sensor has detected wildfire:

1) WILDFIRE DETECTED BY GATEWAY_01 AT MOSHONO_WEST DUE TO HIGH_TEMPERATURE;

2) WILDFIRE DETECTED BY GATEWAY_01 AT MOSHONO_WEST DUE TO LOW_HUMIDITY;

3) WILDFIRE DETECTED BY GATEWAY_01 AT MOSHONO_WEST DUE TO THICK_SMOKE.

The words in italics indicate the location of the gateway which will give the probable location of where the wildfire has been detected. The location information is pre-defined in the gateway node controlling code based on area where it is deployed. GPS module is not used in order to reduce cost as well as power consumption by the sensing nodes during location search. After constructing that message the gateway node sends that message to the control center through the GSM/GPRS module.

When the villager living near the forest reserves witnesses any wildfire incidence, he/she constructs a message with the following words: "WILDFIRE SEEN AT MOSHONO_WEST", the words in italics being the location of that wildfire incidence and sends that message to the monitoring center. When the villager 


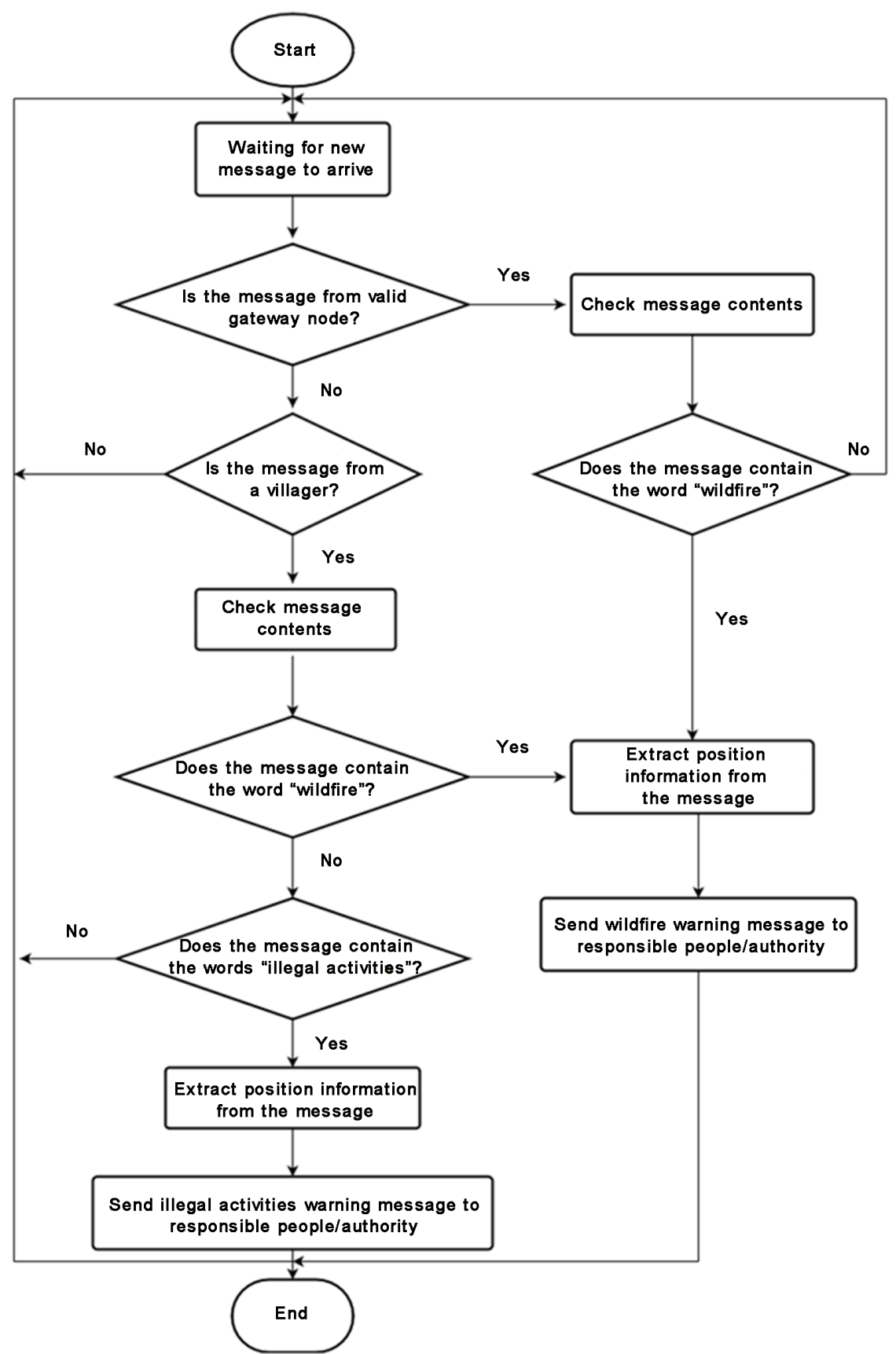

Figure 6. Functional flowchart at the control center.

witnesses any illegal activities that are taking place at a certain location of the forest or reserved national parks he/she constructs a message with the following words: "ILLEGAL ACTIVITIES SEEN AT MOSHONO_WEST", the words in italics being the location where that particular illegal incidence is taking place and then sends that message to the control center.

When the control center receives the message it first compares the sender's phone number with phone numbers stored at the contact group called "Gateway" of messaging service designed on Telerivet platform to see whether it matches 
one of the contact numbers stored there. If it matches one of the phone numbers stored at the "Gateway" contact group it means it is a message from a valid Gateway node of the Wildfire Monitoring and Detection System. The messaging service will then scan the message contents to see whether it contain a word "wildfire". If there is no such a word the message received will be discarded and the messaging service will wait for a new message to arrive. If there is such a word, the messaging service will extract location information from that message and construct any one of the following messages depending on the type of wildfire notification received:

1) THERE IS WILDFIRE DETECTED BY GATEWAY_01 AT MOSHONO_ WEST DUE TO HIGH_TEMPERATURE, PLEASE TAKE APPROPRIATE ACTION NOW BEFORE IT IS TOO LATE!!!

2) THERE IS WILDFIRE DETECTED BY GATEWAY_01 AT MOSHONO_ WEST DUE TO LOW_HUMIDITY, PLEASE TAKE APPROPRIATE ACTION NOW BEFORE IT IS TOO LATE!!!

3) THERE IS WILDFIRE DETECTED BY GATEWAY_01 AT MOSHONO_ WEST DUE TO THICK_SMOKE, PLEASE TAKE APPROPRIATE ACTION NOW BEFORE IT IS TOO LATE!!!

The words in italics being the location information extracted from the message sent by the gateway node.

If the message is not from a valid gateway node, the messaging system will check whether it is from a villager living around the forest by comparing the phone number of the sender with the contact numbers stored at the "Villagers" contact group on the messaging service. If the phone number of the sender is not available at the "Villagers" group the message will be discarded and the messaging service will wait for a new message to arrive. If the phone number of the sender matches one of the phone numbers stored at the "Villagers" group it means the message is indeed from a villager living nearby that forest. The messaging service will then scan the message contents to see whether it contain a word "wildfire or words "illegal activities". If it contains the word "wildfire" the system will extract location information from the message received and then it will construct a notification message with words: "THERE IS WILDFIRE AT MOSHONO WEST, PLEASE TAKE APPROPRIATE ACTION NOW BEFORE IT IS TOO LATE!" The words in italics being the location information extracted from the message received. The message will then be sent to the responsible authorities. Otherwise, if after scanning it is found out that the message does contain the words "illegal activities", the system will extract location information from the message received and construct a notification message with words: "THERE IS ILLEGAL ACTIVITY TAKING PLACE AT MOSHONO WEST, PLEASE TAKE APPROPRIATE ACTION NOW BEFORE IT IS TOO LATE!” The notification message will then be sent to the responsible authorities.

If the messages received by the messaging service do contain words "wildfire" or "illegal activities" but the sender's phone number does not match any of the 
phone numbers stored at either "Gateway" contact group or "Villagers" contact group a reply message will be sent to that sender with the following words: "PLEASE REACH ME VIA MY OTHER MOBILE PHONE NUMBERS".

All the events at the control center (the receiving of messages from either the gateway or a villager, the construction of notification messages for wildfire incidence or illegal activities incidences and the sending of those notification messages to the responsible authorities) will take place automatically without human intervention. The main reason is to speed up the notification process to the responsible authorities for them to take controlling measures as quickly as possible.

\section{Experimental Set-Up and Results}

During testing of this system, 4 sensing nodes, 1 gateway node, 2 mobile phone handsets (one to act as a villager, and the other to act as responsible authority), 1 android phone with Telerivet software installed and 1 laptop (where rules to control messages uploaded to the Telerivet cloud were written) where used. Sensing nodes and gateway node prototypes where deployed at a remote place in Arusha region. The location where the gateway node was deployed was named MOSHONO_WEST. Two people, one with a mobile phone acting as a villager and the other with a mobile phone acting as a responsible authority stood few kilometers apart from each other about 2 to 3 kilometers away from where the gateway node was deployed. The laptop and the android phone were placed in another place where there was access to internet. Figure 7 and Figure 8 below shows the system prototypes and the experimental setup respectively.

The sensing nodes where exposed to controlled actual fire and smoke made by burning some dry grasses and pieces of fire woods. The system was able to detect fire and immediately send warning messages to the mobile phone of a person acting as responsible authority. The person acting as a villager was asked to send notifications messages about fire or illegal activities to the control center and the system was also able to send respective warning messages to the mobile phone of a person with a mobile phone acting as responsible authority. Figure 9 and Figure 10 show some of the messages received by a mobile phone of a person acting as a responsible authority.

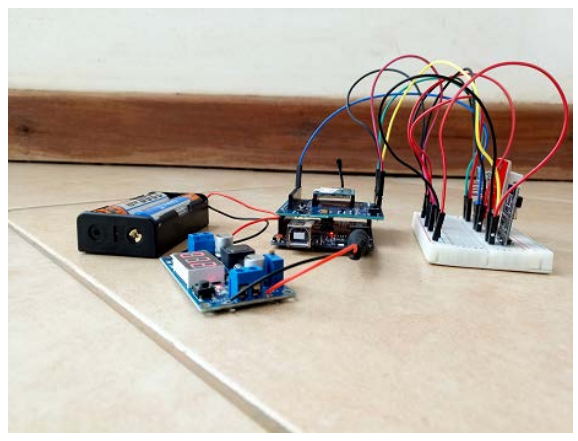

(a)

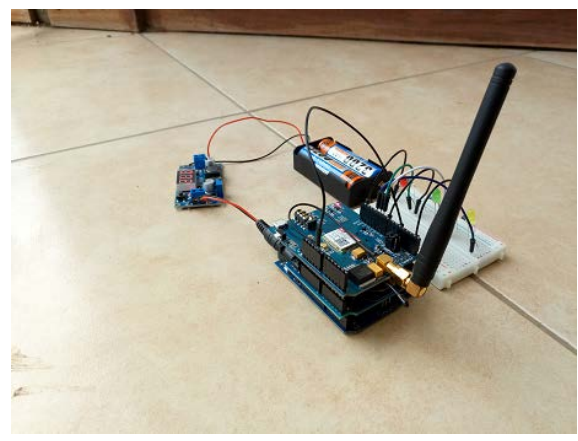

(b)

Figure 7. (a) Actual prototype of the sensing node; (b) Actual prototype of the gateway node. 


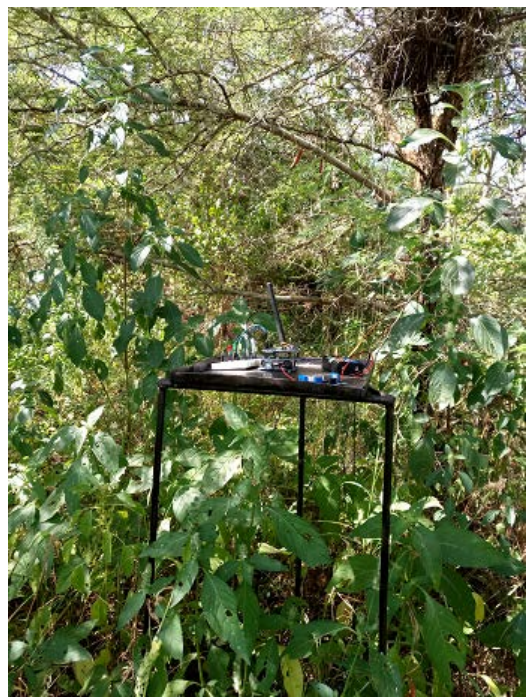

(a)

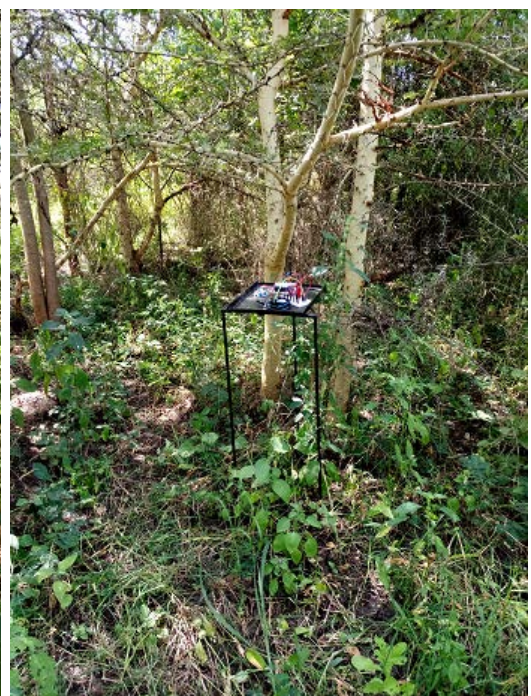

(b)

Figure 8. (a) Gateway node deployment; (b) Sensing node deployment.

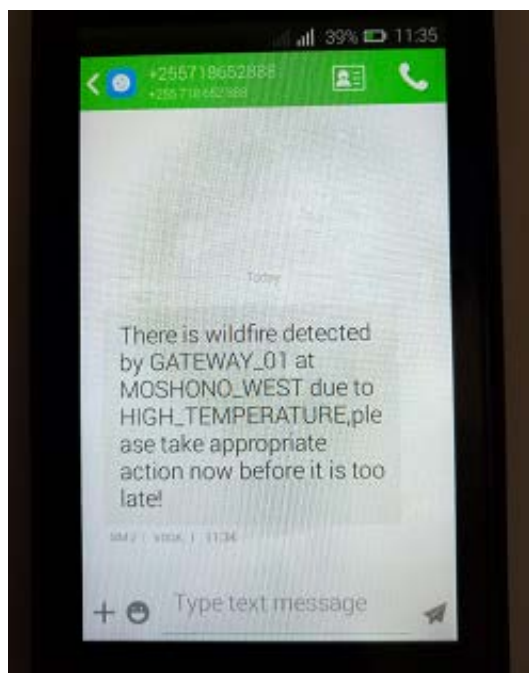

(a)

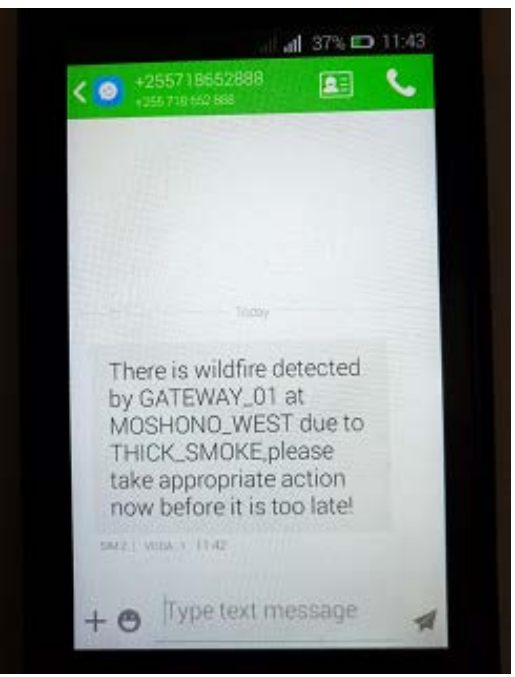

(b)

Figure 9. (a) Text message sent to the responsible person after a sensing node has detected fire due to high temperature; (b) Text message sent to the responsible person after a sensing node has detected fire due to presence of smoke.

Figure 9(a) and Figure 9(b) show screenshots of messages sent to responsible people/authority after the sensing node has detected fire incidence. The responsible people can use any kind of mobile phone; it can be a feature phone or a smart phone. They can also use any SIM (Subscriber Identity Module) card, from any telecommunication company of interest to be able to receive warning notification about wildfire. The messages received contain probable location of where fire is, in order to enable responsible people to locate it as quickly as possible, to give them enough time to control it.

Figure 10(a) and Figure 10(b) show screenshots of messages sent to responsible people/authority after a villager has sent warning messages to the control 


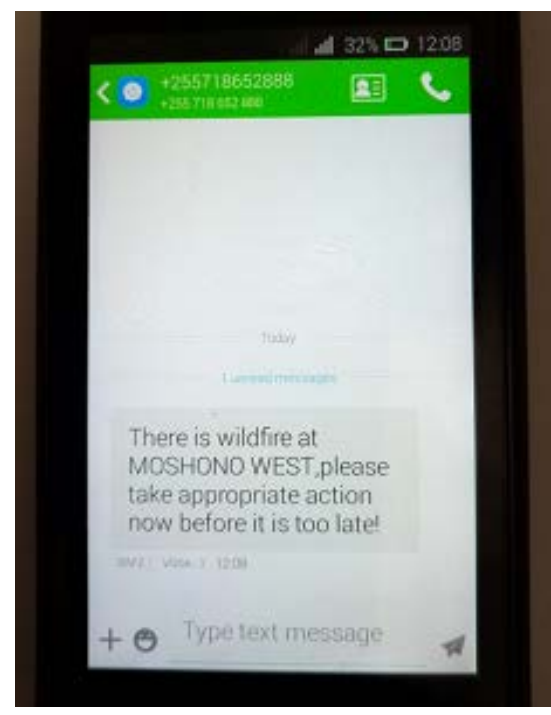

(a)

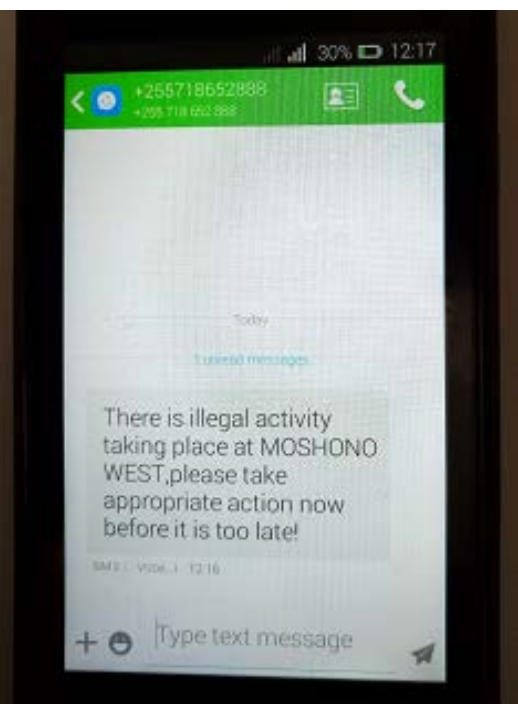

(b)

Figure 10. (a) Text message sent to the responsible person after a villager has sent wildfire notification to the control center; (b) Text message sent to the responsible person after a villager has sent illegal activity notification to the control center.

center after witnessing wildfire or illegal activities incidences in forests. The villagers can use any kind of mobile phone to send warning messages to the control center; it can be a normal feature phone or smart phone. In order to be able to send warning messages to the control center, they are free to use any type of SIM card, from any telecommunication company available in Tanzania. The messages sent to the responsible people/authority contain the probable location of where wildfire or illegal activity has been witnessed by the villager as well as the type of event witnessed (whether it is wildfire or illegal activity). This will enable the responsible people/authority to locate the location of wildfire or illegal activity witnessed as quickly as possible to give them enough time to take controlling measures.

\section{Conclusions}

In order to be able to effectively control wildfire, there should be mechanisms to detect it immediately as soon as it occurs and inform responsible people/authority so that they can take appropriate measures as quickly as possible. Any failure or delay to inform responsible people about wildfire on time will result in the fire becoming very huge to the extent that controlling becomes almost impossible leading to irreversible damages, distraction of infrastructures and other valuable properties, deaths of people as well as wild animals.

There are a number of systems around the world for monitoring and detection of wildfire but most of them can't be deployed and used in developing countries like Tanzania due to several issues such as absence of reliable internet coverage within forests, high power consumption as well as lack of technological infrastructures to support smooth operation of the systems. 
The contributions of the work proposed in this paper to already existing systems for monitoring and detection of wildfire based on wireless sensor network can be seen in three aspects; the sensing and gateway nodes can be deployed in areas where there is no reliable internet coverage, a scenario common in forests and national parks in developing countries like Tanzania. This is achievable through the use of short message services available in mobile cellular network. The second contribution is the involvement of communities living around forests or national parks in conserving the environment by giving them a means of reporting wildfire or illegal activities taking place in forests or national parks to responsible people/ authority by using their normal feature phones. This is achievable because almost every village household has got at least one feature phone due to having cheaper prices. The last main contribution is its ability to send warning messages about wildfire or illegal activities to responsible people/authority automatically without human intervention. There is no need to have people staying all the time at the control center to monitor wildfire or illegal activities taking place in forests and national parks.

This work can be further extended by designing an efficient solar or wind energy harvesting system to provide reliable power to the system.

\section{References}

[1] Alkhatib, A.A.A. (2014) A Review on Forest Fire Detection Techniques. International Journal of Distributed Sensor Networks, 2014, Article ID: 597368. https://doi.org/10.1155/2014/597368

[2] Vicente, F.B., Carbajal, N., Felipe, L. and Martínez, P. (2014) Estimation of Total Yearly $\mathrm{CO}_{2}$ Emissions by Wildfires in Mexico during the Period 1999-2010. Advances in Meteorology, 2014, Article ID: 958457.

[3] Zhao, Y., Zhou, Z. and Xu, M. (2015) Forest Fire Smoke Video Detection Using Spatiotemporal and Dynamic Texture Features. Journal of Electrical and Computer Engineering, 2015, Article ID: 706187. https://doi.org/10.1155/2015/706187

[4] Rücker, G. and Tiemann, J. (2012) Project Report: Eleven Years of MODIS Burned Area : A GIS Analysis for the Territory of the United Republic of Tanzania.

[5] FAO (2013) A Fire Baseline Report for Tanzania.

[6] Bolourchi, P. and Uysal, S. (2013) Forest Fire Detection in Wireless Sensor Network Using Fuzzy Logic. 5th International Conference on Computational Intelligence, Communication Systems and Networks, Madrid, 5-7 June 2013, 83-87.

[7] Lloret, J., Garcia, M., Bri, D. and Sendra, S. (2009) A Wireless Sensor Network Deployment for Rural and Forest Fire Detection and Verification. Sensors, 9, 87228747. https://doi.org/10.3390/s91108722

[8] Molina-Pico, A., Cuesta-Frau, D., Araujo, A., Alejandre, J. and Rozas, A. (2016) Forest Monitoring and Wildland Early Fire Detection by a Hierarchical Wireless Sensor Network. Journal of Sensors, 2016, Article ID: 8325845. https://doi.org/10.1155/2016/8325845

[9] Wang, M., Liu, H., Chen, F. and Liu, J. (2015) Forest Fire Warning System Based on GIS and WSNs. 4th International Conference on Advanced Information Technology and Sensor Application, 21-23 August 2015, Harbin, 3-6. https://doi.org/10.1109/AITS.2015.8 
[10] Chauhan, A., Semwal, S. and Chawhan, R. (2013) Artificial Neural Network-Based Forest Fire Detection System Using Wireless Sensor Network. India Conference, Mumbai, 13-15 December 2013, 1-6. https://doi.org/10.1109/INDCON.2013.6725913

[11] Zhang, J., Li, W., Han, N. and Kan, J. (2008) Forest Fire Detection System Based on a ZigBee Wireless Sensor Network. Frontiers of Forestry in China, 3, 369-374. https://doi.org/10.1007/s11461-008-0054-3

[12] Hefeeda, M. and Bagheri, M. (2009) Forest Fire Modeling and Early Detection. Ad Hoc \& Sensor Wireless Networks, 7, 169-224.

[13] Owayjan, M., Freiha, G., Achkar, R., Abdo, E. and Mallah, S. (2014) Firoxio: Forest Fire Detection and Alerting System. 17th IEEE Mediterranean Electrotechnical Conference, Beirut, 13-16 April 2014, 177-181. https://doi.org/10.1109/MELCON.2014.6820527

[14] Banzi, M. (2009) Getting Started with Arduino. O’Reilly Media, Inc., Sebastopol.

[15] Faludi, R. (2011) Building Wireless Sensor Networks. O’Reilly Media, Inc., Sebastopol.

[16] SIMCom (2017) SIM800C. http://simcomm2m.com/En/module/detail.aspx?id=74

[17] Telerivet (2015) Telerivet Messaging Platform. https://telerivet.com/

[18] Neumann, M. (2016) TextTETEA-An SMS-Based Education Service. Global Humanitarian Technology Conference, Seattle, 13-16 October 2016, 312-315.

\section{Submit or recommend next manuscript to SCIRP and we will provide best} service for you:

Accepting pre-submission inquiries through Email, Facebook, LinkedIn, Twitter, etc. A wide selection of journals (inclusive of 9 subjects, more than 200 journals)

Providing 24-hour high-quality service

User-friendly online submission system

Fair and swift peer-review system

Efficient typesetting and proofreading procedure

Display of the result of downloads and visits, as well as the number of cited articles

Maximum dissemination of your research work

Submit your manuscript at: http://papersubmission.scirp.org/

Or contactwsn@scirp.org 